\title{
The analysis and design of urban wetland: the Water Garden in Portland and Living Water Park in Chengdu as case studies
}

\author{
Z. Zeng \& B. Li \\ Huazhong University of Science, Technology, China
}

\begin{abstract}
Problems caused by urbanization, such as inadequate water content in the urban foundation, ecological imbalance in the soil and the heat island effect, have become issues that people pay a great amount of attention to. Two projects, cited as being successful in integrating urban landscape planning and wetland ecology, are the Water Garden in Portland, USA, and the Living Water Garden in Chengdu, China. An artificial wetland is effective in establishing urban ecology. It may not only solve the problem of the urban water crisis, but also brings a series of good eco-environmental effects, such as the conservation of groundwater, regulation of climate, extending green areas, purifying the air, beautifying a city, and even effectively controlling flood damage, etc.

Keywords: rainwater infiltration, artificial wetland, city ecology.
\end{abstract}

\section{Introduction}

With the over exploitation of soil resources in urban development, the length and breadth of land that was utilized for agricultural or forestry purposes or as natural habitats of animals or plants, has been unearthed by architectural changes in many landscape areas. Industrial land, traffic sites and large numbers of concrete buildings, as well as other sorts of land impervious to water, have taken the place of the original land to become the main part of the urban foundation.

This phenomenon seriously affects the natural infiltration of precipitation and causes surface runoff to collect relatively together, which may result in urban floods, serious water shortage in urban foundations and disturb the balance of the soil, thus cutting off the natural cycle in an urban environment. Meanwhile, a fog is formed by exhaust gases that cover the city and traps radiation heat in the air, 
which cause higher temperatures in the city and leads to the formation of an urban heat island. Moreover, the hardening of the urban land leads to ecological imbalance and pollution. All of the above factors focus on what occurs daily.

\section{Wetland and water gardens}

Lately, in the process of urbanization, wetland resources have become more and more relevant to the city, not only because of their site but also in view of social, economic, and ecological reasons. As a result, the existence of wetland faces great challenges. It warns us to re-explore and re-consider the relationship between humans and nature in the urban development process.

Wetland as a special ecotype first came into research in the 1970s. To be brief, wetland is an ecotype between land and water. The conception of a Wetland Park is similar to that of a small protection zone, yet somewhat different from the general sense of natural protection areas and parks. According to the recent trend of domestic and foreign wetland protection and management, wetlands involve species and habitats protection and ecotourism, as well as environmental education under the entitlement of a Wetland Park.

A Wetland Park can prosper a local economy and offer a site for citizens to recreate and enjoy wetland sceneries. What's more, a Wetland Park may become a special area for local residents to protect their culture formed in the long-term process of living around wetland; it might even become an important element and component of a city's features, distributing benefits to various communities.

\section{Water garden, Portland, Oregon, USA}

About ten years ago, a water infiltration experiment was conducted in Portland, Oregon, concerning the annual months of almost continuous rain that brought people to conceptualize their original solution that is spreading and being

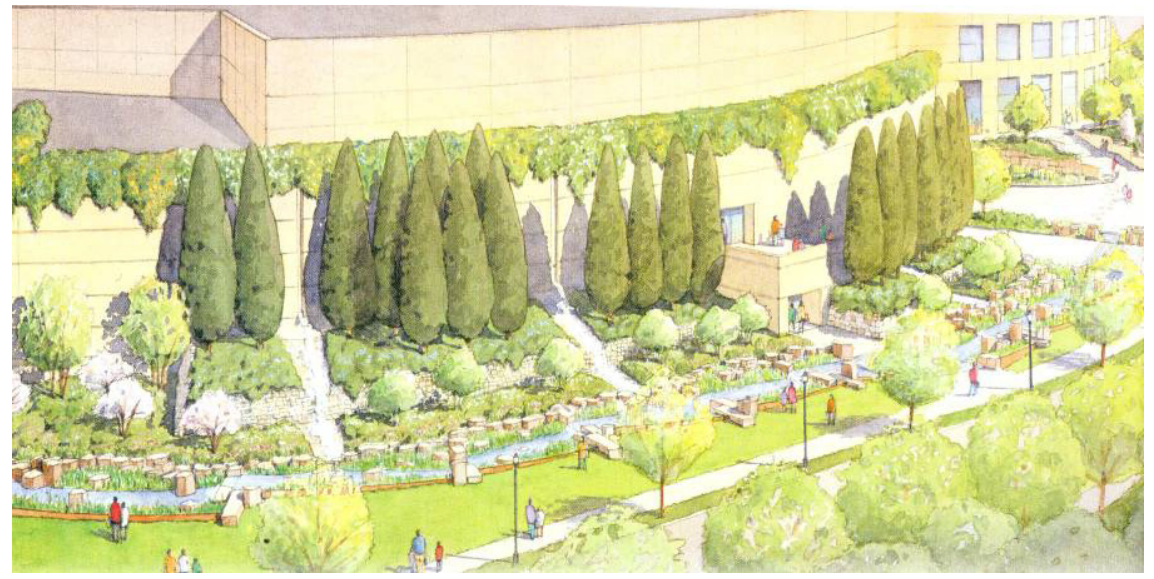

Figure 1: Water garden of Portland. 
imitated throughout Portland. In this experiment, Murase, a Portland landscape designer, with his cooperators designed the rain garden, pervious to most or all of the runoff from the parking lot.

This extraordinary rain park, designed by Reed Meyer Architect, can infiltrate water from the roof of the Oregon Convention Center, with the East Bank building being the largest of the tested buildings. In this project, rainwater is collected in the 33.38-acre roof, delivered to the garden through tubes on the conference centre's south side and then seeps into the ground.

In many parts of Portland, prevention of rainwater problems caused by drainage overload shall be listed as a principal issue. However, this is not the case here. With the Huila River flowing ten meters away, rainwater can be discharged into the river smoothly. The designers' main goal is to improve water quality by absorbing rainwater and filtrating micro-organisms inhabiting plants,

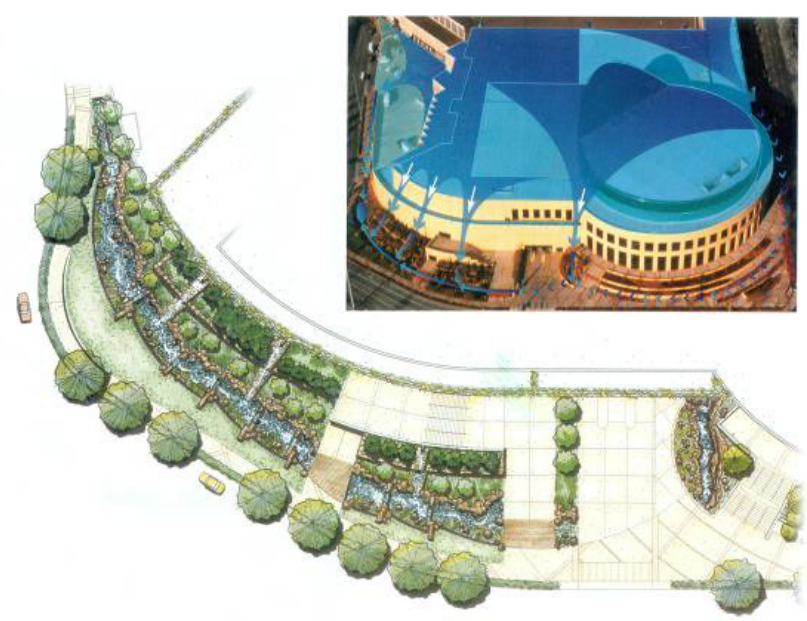

Figure 2: $\quad$ Plan of water garden.

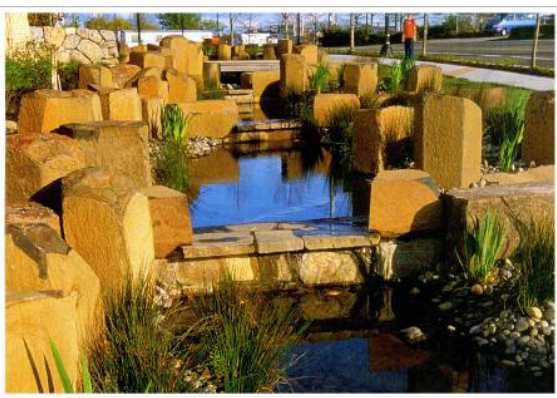

Figure 3: $\quad$ The pool system. 
roots, and the soil (the majority of the micro-organisms are motes in vehicle exhaust gases).

The Portland Garden contains the following systems.

\subsection{Pool system}

Rain garden, through a series of shallow, small waterfalls as well as serieswound pools separated by basalt weirs, slows down the speed of the water flow. When each pool is filled to capacity, the rain water then overflows falling 46 centimetres to the next pool and leaving sediments stably in the primary one. The whole artificial ditch is 969 meters long and 1.8 meter wide on the average. In this way, the pools slow down the speed of water flow and not only save water but also provide sufficient time for water to infiltrate into the underground.

\subsection{Stone system}

The bottom of the ditch in the rain water park is mainly made up of pale green slate, allowing water to flow smoothly to the top. Meanwhile cobblestones on the edge of the ditch make way for water to infiltrate into the underground while rough basalts walling the ditch create an artless and natural atmosphere. All these vivid and dramatic details combining both the dynamic and the static embody the designer's profound understanding on the law of nature, penetrating discernment and high standard of design. Meyer Reed's design of the main ditch can be viewed as perfect in the composition of the Northwest Pacific stones, embodied in the following five aspects.

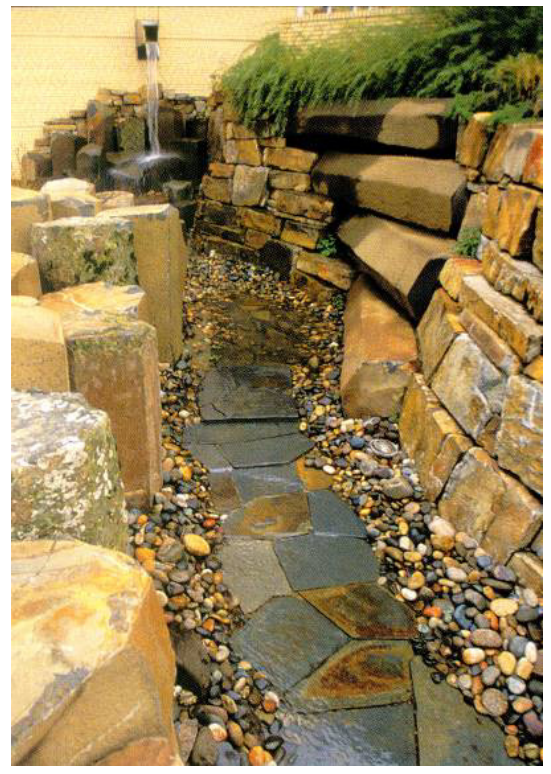

Figure 4: $\quad$ Stone system.

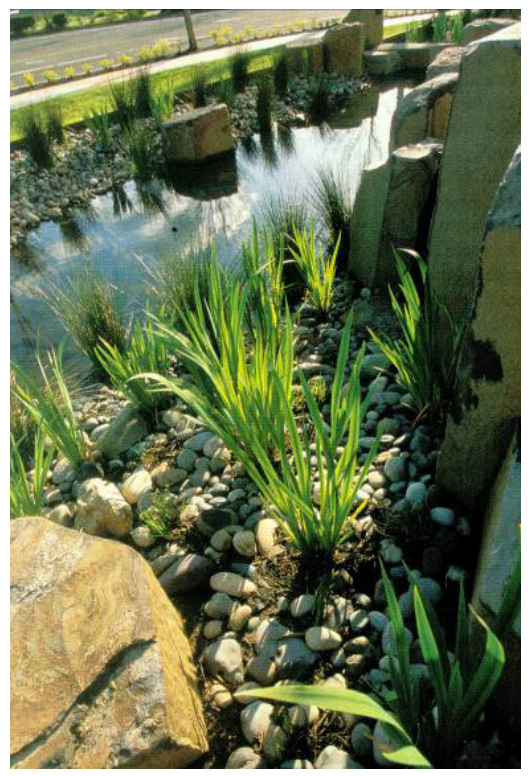

Figure 5: $\quad$ Plant system. 
The bottom of the ditch made of hard slates produced in a quarry on the border of Washington and Idaho.

River stones utilized to fix the slope on the side of the whole system come from Montana's colourful quarry, with diameters varying between 2 centimetres and 10 centimetres.

In order to direct the spillway to spread along the length, the origin of the ditch uses a retaining wall, which is built up with solid stones from Montana. Vertical elements along the ditch's length are composed of cylindrical bronze basalts from the district of Moses Lake in Washington. The wide and dry wall as well as the eroding pool of the deposition pond on the building's south apply basalts outside of Camas, Washington.

\subsection{Plant system}

Lots of aquatic plants are planted on both sides of the drain to create natural ecological environment of artificial wetlands. These plants, growing up from gaps between pebbles and gravels, add a green colour to the rain garden and make it more vivid, lively and natural, but also play the role of a depurative agent, absorbing a variety of harmful pollutants, such as grease washed down from the adjacent roads. In addition, the plants and its root system can firmly fix gravel and sand to prevent against long-time water erosion.

Theoretically speaking, the systems mentioned above are proved to have the capability to allow plenty of water to infiltrate into the underground, especially during short continuous flurries. What is the rate of rain infiltrating into the soil during the heavy downpour? It is difficult to cite convincing data to answer this question, for in practice no one is there to inspect the performance of the system. However, Bill Cop, the project engineer, has introduced plenty of signs such as the phenomena that water does not stay in the pool for a long time, showing that lots of water is being absorbed. In a heavy rain, water overflowing the cascading pools finally influx into the lowest pool. Water runs over the lower pool through a siphon and flows into a 76 centimetre public drainage pipe.

Generally speaking, the rain garden in the extension of the Oregon Convention Center deals with the storm water issue very successfully. It won the annual award for the best water conservation in Portland. As a project combining water, supervision, and celebration; the rain garden deserves wide dissemination as a model.

\section{Living water garden, Chengdu, Sichuan province, China}

The garden, an appealing urban park that grew out of a larger project to improve the water quality of the Fu-Nan River, covering six acres along the banks of the $\mathrm{Fu}-\mathrm{Nan}$ River near the centre of the city of Chengdu in western China, is an elegant example of environmental education [2]. 


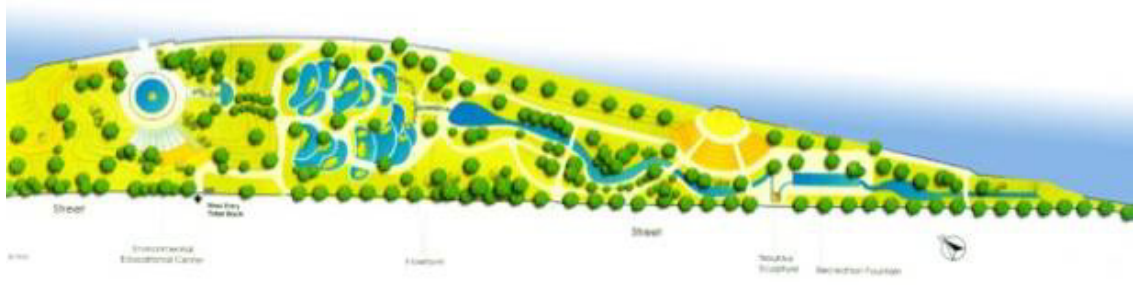

Figure 6: $\quad$ Plan of the living water garden.

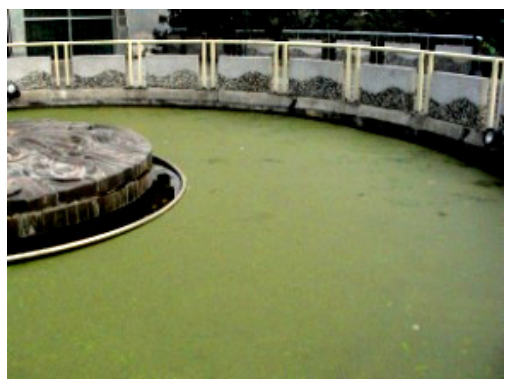

Figure 7: Anaerobic settling tank.

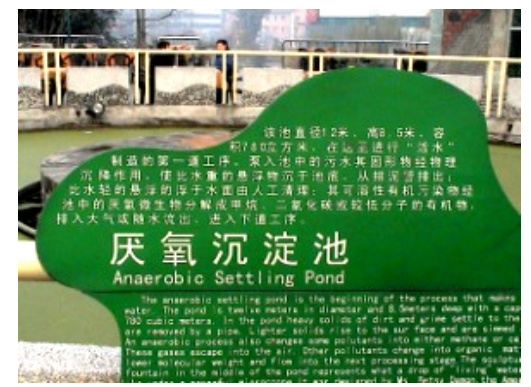

Anaerobic settling tank.

\subsection{Overview}

Living Water Park is China's first water theme park of the city's ecological landscape. Water is collected from the polluted Fu-Nan River, and flows through the park's wetland purification system, and finally returns into the river. Battersea Damon, an American artist and water protector, first proposed the conception of the living water garden and won Chengdu's government support. She organized artists as well as water conservancy, city planning and landscape engineers from China, America, and South Korea to design and construct the garden, which covers an area of 2.4 hectares and has great cultural, artistic, and ecological significance.

\subsection{The water-treatment system}

Wetland Park covers an area of 0.2 hectares, and the capacity of sewage purification is 200 cubic meters each day. It removes bacterial pollutants and heavy metals in the water and returns it to the river. Contaminated water (usually equal to or lower than the water quality GB3838V) is pumped into anaerobic sedimentation tanks from the Fu-Nan River where anaerobic micro-organisms decomposition occurs in physical sedimentation.

The process allows most of the solid matter in the water to accumulate at the bottom or float on the surface, in which part of the solvable organic matter will be broken down into $\mathrm{CO} 2, \mathrm{CH} 4, \mathrm{H} 2 \mathrm{O}$ and $\mathrm{N} 2$ while some of the simple organic 
matters will be degraded. Water coming out from the anaerobic pond flows through sculptures and into the oxygen tanks, and gets degraded once more by aerobic micro-organisms and then flows into two sets of plant-ponds and plantbed treatment system. This system is composed of five lively pond plants and 12 plant-beds. Water pollutants, when flowing through the whole system, experience adsorption, filtration, oxidation, revivification, decomposition and gradually degrade into nutrients available for flora and fauna. Water coming from the treatment system flows through several water sculptures and goes into three fish ponds successfully. To ensure that dissolved oxygen in the water meets the needs of the growth of fish, two circumfluence items of equipment are used to return part of the water into the plant pond to increase dissolved oxygen and up-grade the water quality to meet GB3838--88III. Part of the water from the fish pond can be pumped back into the park for landscape use while the rest inflows Paddling Pool and back to Fu-Nan River. Every day up to 200 cubic meters of water flows through the water park. Although this is not enough to change the quality of water in Fu-Nan River, it does allow visitors to see the process in which "dead water" is gradually activated, purified, and finally flows as clean water.

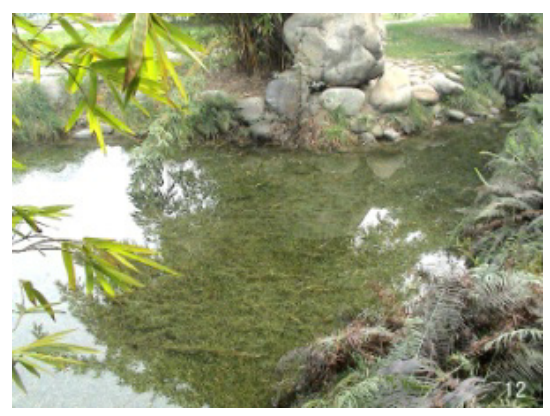

Figure 9: Living water.

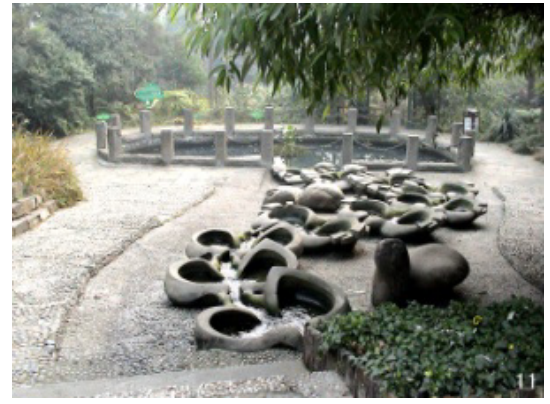

Figure 10: Sculpture of living water.

\subsection{The art of the garden}

The living water park's core park, the plant river as well as the plant-bed group are located in the fish stomach. This shape imitates Huanglong travertine pool group on Sichuan. Wooden trestles set up between ponds are in a rural style. Three fish ponds and fountains as well as paddling ponds show at the tail of the fish. Plant blocks, plant-bed groups, planted duckweed, water hyacinth, pond lilies, etc. which are tested out to have strong water purification capacity, adaptability and visual value, park slopes imitating Emeishan Mountain's microclimatic and natural vegetation, plant pond, raised beds and restocking of fish ponds with ornamental fish and frog, etc. all form a symbiotic system of the fauna and flora in the water environment. Visitors can see the water treating process and the phenomena that the quality of water upstream is poor which accommodates sparsely any life, for example, no fish but only few duckweed 
algae and very few plants exist in the anaerobic pool and oxygen tank. With step by step purification, the higher the grade of the flora and fauna, the better the growth of plants, indicating that life and water are interdependent with each other. As the garden provides a living environmental education classroom, it attracts groups of teachers and students. Some parents take their children to gather around the pool for an "eco-environmental class" experience. Some middle school students even apply to participate in water analysis and protection. The living water garden is not the one and only public facility for education on water purification. Water labouring park designed by Lorna Jordan (referring to "the art of cleaning", Landscape

Architecture, Jan. 1997) as well as College Padillas Elementary in L.A. designed by Campbell Okuma Perkins associates, play a similar role to that of the living water garden in Washington and New Mexico. There are also some public facilities on water purification education, such as Wuhan hydrobiology institute.

However, the living water garden wins special achievements since it is located in the centre of the city and has strong affinities. Other projects locating remotely, for example, the municipal waste water factory, cannot provide as sites for everyday entertainment and relaxation while the living water garden can. Water purification details inspire people's instinctive curiosity towards science and natural environment. Sculptures, platforms as well as all other sorts of design elements can be appreciated just for their beauty. Paths in the woods, verdant plants and lawn offer a perfect place for recreation in the city. This park is designed to upgrade citizens' organization to protect the environment. As a result, designers did not try to reforge a natural environment. Visitors clearly know the fact that they are in the artificial water park environment. The conception of the park is close to public art rather than natural protection in most artists' eyes.

Both the rain water park and the living water park are achievements with efforts of landscape designers, biologists, as well as architects. Designers integrate water bodies, introduce favourable elements to the parks, and pay adequate attention to the park's merits and demerits, both allowing plants, soil, as well as water to function properly in urban space. Both parks are upgraded rather than harm the living environment of the districts they're located in. Soil, water, and plants stay in harmony with the people in the city space.

\section{The ecological significance of urban wetland}

\subsection{Wetland increases the capacity of water storage and purification and the water content of the city foundation}

Many problems exist in city foundations, such as too much hard ground and serious water loss. As a result, it is difficult for rain to return to earth, causing serious damage to the capacity of natural water retention and resulting in shallow underground water that quickly dries out. Rain gardens and living water gardens can solve this problem effectively: on rainy days, the living water garden and rain garden can store water. They slow down the speed of water with shoals, 
small waterfalls, and series-wound pools. Moreover, they can accommodate plenty of water that infiltrates into the underground. Water superfluously flows through open ditches and into public drainage pipes, releasing much pressure on the public drainage systems and other municipal facilities.

\subsection{Vegetation's role with regards to regulating climate leads to reducing pollution and controlling the urban heat island effect}

Because of the impelling force produced by photosynthesis, plant pump can transport most of the water from the roots to the leaves, as water evaporates into the air and takes the heat away. There are sharp differences of temperature between each side of the leaves and the plant pump consumes a lot of heat in the process of transporting water from roots to leaves, enabling effective absorption of large amounts of radiation and heat in cities, as well as regulation of air, temperature, and humidity.

The photosynthesis of plants and its features such as the capacity to store and filtrate water, ability to regulate temperature, radiation, air humidity, as well as its cleansing ability makes an impact on urban management and digestion of city noises which all perform to improve eco-city micro-environment.

As far as the green house effect caused by compaction of urban space, vegetation photosynthesis is effective to regulate concentration of carbon gases and produce oxygen in the centre of cities. Furthermore, vegetation can absorb urban radiation, regulate air temperature and humidity, and improve urban climate.

What's more, vegetation in wetland park has adsorption and absorption capacities and can degrade air pollutants and partly absorb the air and rainwater contaminants containing nitrates or other harmful substances. Vegetation growth which consumes a lot of carbon and releases oxygen, improve urban air quality. And vegetation can effectively muffle noise and reduce the impact of noises on citizens' life. Contaminants adsorbed and clotted can be utilized and absorbed as nourishment.

\subsection{The role of biodiversity conservation}

A vegetation corridor and an urban water system can be combined as the "urban ecological corridor" of the urban structure. Urban ecological corridor and urban cold bridge coexist and provide fresh air for cities, reducing the impact imposed on cities by urban heat island effect and restoring urban ecological chain which has been destroyed.

Plants and waters in the living water park and the rain garden provide a site for birds and insects unusual in cities to habitat, and extend as ecological corridors. The scene that children kneel, sit, or lie beside water, observing insects and fish living and existing in every wetland park, promoting children's instinct to be curious, though nowadays not many cities offer a water park that satisfies the longing to observe nature directly. 


\subsection{The educational value of the ecological environment}

The water purification system of the living water garden is not aimed at great improvement in water quality. Take the Fu-Nan River for example; the water quality can be greatly improved only by reducing the amount of discharged pollutants. Actually, the living water garden is designed to help Chengdu citizens to realize that the progress of their environmental awareness along with a sense of pride for their city can inspire them to protect the environment and improve it. In many aspects both of the gardens located in China and the U.S interpret the environmental theme. They are successful and can be viewed as integrated and vivid examples of urban ecological wetland design and have profound influence on people's environmental sense.

\section{Conclusion}

Urbanization is progressing with accelerated rate in China. In this process, outskirt wetlands such as lakes, rivers, pools and swamps are resources irreproducible once they are destroyed. The protection and utilization of wetland resources, such as to reconstruct them into urban wetland parks or urban ecological parks or other sorts of public green spaces, are favourable for the formation of a city's characteristics.

The living water garden as well as the rain garden in the city can effectively protect, clean-up, and beautify nature and offer citizens a chance to get close to it. They create a good ecological environment for various urban species with comfortable, healthy, safe and nice living conditions for residents. Of course, the anfractuous and ever-changing urban environmental issues are impossible to be accomplished in an action. Final settlement of the problems of cities depends on humanity's reflection and the development of science and technology to the comprehension management of urban environment, recovery and regeneration of the urban eco-virtuous circle. Yet in any case, living water park and rain water garden provide as important examples in the field of creating urban ecological spaces, proving that people can effectively regulate and improve urban development through design as well as by utilizing landscape conception and urban ecological engineering principals. In this way, people can restore satisfying urban environment and living space. Living water park and rain water garden are fruits of the combination of biological science and landscape architecture. They start a revolution in the process of urbanism in "landscape, biological science, and architecture", and provide an effective way in creating urban ecology.

\section{Acknowledgement}

I would like to thank Mr. Xingliang Zhang for his company when I visited the living water garden. 


\section{References}

[1] J, William, Thompson. 2004, 9. Landscape architecture.

[2] Mari, Padova. 2004, 9. Landscape architecture.

[3] H. Takabayashi, M. Moriyama, Urban heat island phenomena influence by sea breeze, AIJ. Technol. Des.No.21, 2005.6 